12. Общие сведения о Spring Security // github.com. 22 фев. 2013. URL: https://github.com/wizardjedi/myspring-learning/wiki/Spring-security.

13. Сіль (криптографія) // uk.wikipedia.org: вікіпедія. 2018. 28 квіт. URL: https://uk.wikipedia.org/wiki/\%D0\%A1\%D1\%96\%D0\%BB\%D1\%8C_(\%D0\%BA\%D1\%80\%D0\%B8\%D0\%BF\%D1\%82\%D 0\%BE\%D0\%B3\%D1\%80\%D0\%B0\%D1\%84\%D1\%96\%D1\%8F)

\title{
СИСТЕМА СТАБІЛІЗАЦІї КУРСУ МОРСЬКОГО СУДНА, ЧАСТКОВО-ІНВАРІАНТНА ДО ВІТРО-ХВИЛЬОВИХ НАВАНТАЖЕНЬ
}

\author{
Волянська Я. Б. ${ }^{1}$, Голіков В. В. ${ }^{2}$, Мазур О. М. ${ }^{3}$, Онищенко О. А. ${ }^{4}$, Шевченко В. А. \\ 1 - Національний університет кораблебудування імені адмірала Макарова, пр-т Героїв України, 9, Миколаїв, 54000, \\ Україна. \\ 2-5 - Національний університет «Одеська морська академія», вул. Дідрихсона, 8, Одеса, 65029, Україна. \\ ORCID: ${ }^{1} \underline{0000-0002-3010-1684} ;{ }^{2} \underline{0000-0002-4523-2311} ;{ }^{3} \underline{0000-0002-9316-288 X} ;{ }^{4} \underline{0000-0002-3766-3188}$; ${ }^{50000-0003-}$ \\ 3229-1909. \\ e-mail: 1 yanavolyanskaya@gmail.com; $\quad{ }^{2}$ volodymyr.golikov@fms.onma.edu.ua; $\quad 3$ rio.nuoma@gmail.com; 4 \\ oleganaton@gmail.com; ${ }^{5}$ vash4891@gmail.com.
}

Copyright (C) 2018 by author and the journal "Automation technologies and business - processes. This work is licensed under the Creative Commons Attribution International License (CC BY). http://creativecommons.org/licanses/by/4.0

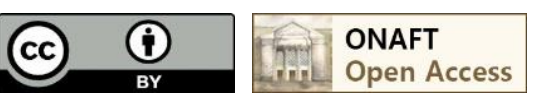

DOI: $10.15673 /$ atbp.v10i1.874

У статті показана можливість застосування у сучасних системах стабілізаџії курсу морського судна принципів частково-інваріантного керування до вітро-хвильових навантажень. Метою статті є встановлення можливостей підвищення точності стабілізації судна на заданому курсі $і$, відповідно, зниження витрати палива за рейс. Мета досягається за допомогою удосконалення алгоритму роботи автокермового. Запропоновано структурну схему двоканальної системи керування, щчо дозволяє: а) виділити точку прикладання основного навантаження; б) провести оцінку впливу, що збурює; в) сформувати передатну функиію коригуючої ланки позитивного зворотного зв'язку за допомогою додаткового каналу керування. Частково-інваріантну систему керування синтезовано на основі спрощеної математичної моделі динаміки судна - моделі Номото другого порядку і ПІД-регулятора, налаштованого на технічний оптимум у припущенні, щьо результуюче навантаження приведено до кута повороту керма. Основна відмінність запропонованої системи керування укладена у використанні принципу непрямої оцінки й виміру збурення за рахунок обробки інформаційних сигналів итатних датчиків судна і його навігаційно-вимірювальної системи. Результат роботи запропонованої системи керування ілюструється математичним моделюванням системи стабілізації курсу морського судна криголамного типу. Моделювання проведено засобами MatLab/Simulink при стрибкоподібних вітро-хвильових навантаженнях, щуо суттєво відхиляють курс судна від заданого значення. При аналізі динаміки запропонованої системи керування використано математичний опис судна, отриманий методами ідентифікації параметрів нелінійної моделі Номото другого порядку. У результаті встановлено, щчо запропонована система має суттєво кращі динамічні властивості - час входження у зону стабілізації $і$ максимальне динамічне відхилення знижуються, приблизно, у 8 разів при умові, щүо обмеження рівня сигналів у системі відсутнє.

Ключові слова: інваріантний, збурення, система керування, автокермовий, курсовий кут, математична модель, динаміка судна. 
http://www.atbp.onaft.edu.ua/

The article shows the possibility of applying the principles of the loads that are partially invariant to the wind-wave affecting the ship's hull and control to the modern systems of stabilization of the course of a marine vessel. The purpose of the article is to establish the possibility of increasing the accuracy of the vessel's stabilization at a given course and, accordingly, reducing fuel consumption over the voyage. The goal is achieved by improving the algorithm of the work of the automatic control system. There has been suggested a structural scheme of the two-channel control system that allows: a) allocating the point of application of the main perturbation; $b$ ) evaluating the disturbing influence; $c$ ) forming the transfer function of the corrective link of the positive feedback using an additional control channel. The partially invariant control system is synthesized on the basis of a simplified mathematical model of vessel dynamics - the second-order Nomoto model and the PIDregulator tuned to the technical optimum in the assumption that the resulting disturbance is brought to the steering angle. The main difference between the proposed control system is the use of the principle of indirect estimation and measurement of perturbation by processing information signals of the ship's regular sensors and its navigation-measuring system. The result of the proposed management system is illustrated by the mathematical modeling of the stabilization system of the icebreaking type of a vessel. The simulation was carried out by means of Matlab/Simulink at hopping wind-wave loads, which significantly deviate from the given value of the ship's course. In analyzing the dynamics of the proposed control system, there was used a mathematical description of the vessel obtained by the methods of the parameters identification of the nonlinear model of the Nomoto second order. As a result, it was established that the proposed system has substantially better dynamic properties - the time of entry into the zone of stabilization and the maximum dynamic deviation is reduced by about 8 times provided that there is no limitation of the signal level in the system.

Keywords: invariant, perturbation, control system, autocurrent, course angle, mathematical model, dynamics of a ship.

\section{Bcmyn}

Необхідність підвищення безпеки мореплавання і експлуатаційних характеристик морських суден призвела до створення різних типів автокермових. Такий електронавігаційний прилад, як автокермовий:

a) автоматично утримує судно на заданому курсі;

б) забезпечує перехід судна з курсу на курс із заданим радіусом або швидкістю;

в) здійснює керування рухом судна по траєкторії при роботі 3 електронною картографічною навігаційноінформаційною системою (ЕКНІС).

Сучасні автокермові забезпечують не лише ефективну стабілізацію курсу судна, але і самонастроювання параметрів системи керування курсом при змінах стану судна (осадки, виду вантажу) і змінах умов плавання (швидкості, погоди, глибини фарватеру). Сучасні системи автоматичного керування курсом (САКК) судна побудовані на основі автокермових і дозволяють зменшити втрати ходового часу до 4 \%, збільшити провізну спроможність судна та знизити витрату палива за рейс на 3-6 \%. У результаті дій автокермового здійснюється ефективна стабілізація руху судна на заданій траєкторії при зниженні втрат потужності суднової енергетичної установки (СЕУ) на керування зниження втрат рискання судна.

Функціонування будь-якої САКК грунтується на використанні математичної моделі динаміки кермового керування судном [1-5]. Природно, чим точніше математична модель динаміки керування судном буде описувати фізичні властивості судна і умови його руху, тим ефективнішу можна синтезувати САКК, тим меншими будуть підсумкові втрати в енергетичній установці судна, знизяться динамічні навантаження на механізми кермової машини судна, шуми і вібрації.

У даний час теорія керування морськими суднами досить добре розвинена і дозволяє побудувати адекватні фізичним процесам руху судна математичні моделі [3, 4]. Математична модель динаміки морського судна, грунтується на шести ступенях свободи руху твердого тіла у просторі $[2,4,5]$, однак, система керування курсом (iї керуючі контролери), що синтезується на основі такої моделі, виходить дуже громіздкою, багато у чому надлишковою і, що суттєво, невиправдано гостро реагує на швидкоплинні зовнішні збурення. Компроміс між складністю математичної моделі і адекватністю моделі реальним фізичним процесам, привів до розвитку різних спрощених математичних описів руху судна $[2,4,6]$.

Міжнародна морська організація (IMO) розробила і прийняла резолюцію А.751 (18), що регламентує необхідність використання математичних моделей динаміки судна при вирішенні практичних задач, що лежать у області безпеки судноводіння [6]. У результаті застосування резолюції А.751 (18) морськими класифікаційними органами рекомендовані для практичного використання у автокермових спрощені математичні моделі судна - моделі Номото першого і другого порядку [1-3, 6, 7].

Модель Номото першого порядку [1-3,4] суттєво спрощена й часто застосовується для повірочних (оціночних, попередніх) розрахунків. Модель Номото другого порядку [6-8] більш ефективна на практиці та описується диференціальним рівнянням:

$$
T_{1} \cdot T_{2}\left(d^{2} \omega / d \omega^{2}\right)+\left(T_{1}+T_{2}\right)(d \omega / d t)+\omega+H(\omega)=K \alpha_{r}+K T_{3}\left(d \alpha_{r} / d t\right),
$$


http://www.atbp.onaft.edu.ua/

де $\omega$ - кутова частота (швидкість розвороту) судна; $H(\omega)=v_{1}|\omega| \omega+v_{2} \omega^{3}-$ нелінійна функція кутової частоти; $T_{1}, T_{2}$, $T_{3}, K, v_{1}, v_{2}$ - параметри математичної моделі; $\alpha_{r}-$ кут перекладки керма.

Практичне використання такої моделі (синтез керуючих контролерів для системи стабілізації курсу [8]) утруднене у зв'язку з необхідністю знання для конкретного судна основних параметрів моделі (1): $T_{1}, T_{2}, T_{3}, K, v_{1}, v_{2}$. Одне 3 простих рішень задачі ідентифікації параметрів рівняння (1) представлено у [9], де враховується, що $d \psi(t) d t=K_{1} \cdot \omega(t)$. У цій формулі позначено: $\psi(t)$ - курсової кут; $K_{1}-$ конструктивний коефіцієнт судна.

Структура сучасних автокермових (NAVPilot xxx Series фірми «Furuno», AP3xхх компанії «Navis Engineering OY», РТ500D компанії «Yokogawa», NautoPilot 5000 і NP2025PLUS компанії «Raytheon», PilotStar D, Saura SA-10, Navitron та ін.) дозволяє гнучко перебудовувати режими їх роботи, враховувати різні чинники і зовнішні впливи. Більшість відомих САКК [1-4, 10-13] використовують у своєму складі класичні ПІД-регулятори і засновані на принципі стабілізації «за відхиленням». Відомо, що існує клас систем керування, заснований на принципах двоканального (інваріантного, комбінованого) керування. Проте цей принцип не застосовується у САКК у зв'язку зі складністю вимірювання зовнішніх збурень, діючих на корпус судна та відхиляючих його від заданого курсу.

Метою дослідження є встановлення можливості підвищення точності стабілізації судна на курсі та, відповідно, зниження втрат енергії, що витрачається на «рискання», за рахунок застосування у САКК принципів інваріантного керування, викладених у класичних роботах Г. В. Щипанова, М. М. Лузіна, Б. М. Петрова.

Зовнішнє навантаження (вітрове, хвильове), що діє на судно, має складний характер і робить основний збурюючий вплив на роботу системи стабілізації курсу (ССК). Попередньо, у найбільш загальному вигляді, розглянемо особливості функціонування систем стабілізації, заснованих на застосуванні принципу двоканального керування.

\section{Основний матеріал}

Нехай для будь-якого моменту часу відомо значення основного збурення й точка його прикладання до системи стабілізації. У цьому випадку, за допомогою введення у систему стабілізації властивостей інваріантності до збурень, можна помітно покращити статичні та динамічні властивості всієї системи без втрати їі стійкості (Г. В. Щипанов, М. М. Лузін). Незважаючи на те, що інваріантні системи керування відносяться до класу систем з компенсацією збурень, у переважній більшості випадків, при практичній реалізації, добитися абсолютної інваріантності до збурень неможливо.

Однією з основних вимог загальної теорії інваріантності $є$ наявність двох каналів передачі збурень (принцип «двоканальності» Б. М. Петрова), що випливає з аналізу роботи динамічної системи, показаної на рис. 1. Відзначимо, що реальні двоканальні системи зазвичай забезпечують часткову компенсацію тільки одного, головного, обраного збурення. Ця компенсація досягається за рахунок зміни структури системи керування - структурної компенсації головного збурення.

Нехай деяке збурення $F(s)$ діє на об'єкт керування $W_{\mathrm{o}}(s)$ у замкненій системі (див. рис. 1$)$.

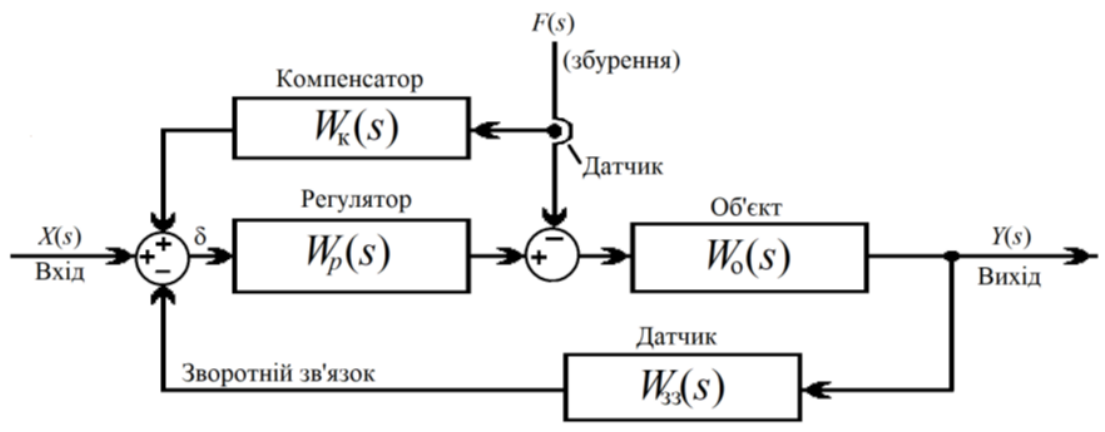

Рис. 1. Структурна схема двоканальної динамічної системи стабілізації

Якби вдалося створити деякий додатковий ланцюг (канал), проходячи через який збурення $+F(s)$ перетворювалося у - $F(s)$, то дія збурення на об'єкт повністю усунеться, що витікає з виразу:

$$
W(s)=\frac{Y(s)}{X(s)}=\frac{X(s) \cdot W_{p}(s) \cdot W_{\mathrm{o}}(s)-F(s) \cdot W_{\mathrm{o}}(s)+F(s) \cdot W_{\mathrm{K}}(s) \cdot W_{p}(s) \cdot W_{\mathrm{o}}(s)}{1+W_{p}(s) \cdot W_{\mathrm{o}}(s) \cdot W_{33}(s)} .
$$

Якщо поставити вимогу $F(s) \cdot W_{\mathrm{o}}(s)=F(s) \cdot W_{\mathrm{\kappa}}(s) \cdot W_{p}(s) \cdot W_{\mathrm{o}}(s)$, то формальною умовою повної інваріантності до $F(s)$ буде виконання співвідношення $W_{\mathrm{\kappa}}(s)=1 / W_{p}(s)$.

Для функціонування такого додаткового каналу необхідно мати датчик збурення $F(s)$ і фізично реалізувати передатну функцію (ПФ) компенсатора $W_{\mathrm{\kappa}}(s)$, зворотну ПФ регулятора $W_{p}(s)$, що дозволить отримати значення збурення зі знаком «мінус» для $F(s)$. 
Якщо коефіцієнти передачі вузла вимірювання $F(s)$ і компенсації $W_{\kappa}(s)$ залишаться незмінними у широкому діапазоні амплітуд і частот, то властивість інваріантності системи керування буде існувати практично для всіх амплітуд і частот збурення $F(s)$, якщо воно, звичайно, не викликає насичення у системі. Саме це і є одним $з$ головних достоїнств будь-яких інваріантних систем керування, оскільки на збурюючий вплив, зазвичай, не накладаються обмеження, за винятком кінцівки його величини.

Проте, для ССК судна практично реалізувати введення сигналу, що компенсує вітро-хвильові збурення які відхиляють судно від заданого курсу, досить складно, оскільки безпосереднє вимірювання збурення пов'язано 3 технічними труднощами, які принципово складно вирішити. Слід зазначити, що реалізація у САКК спостерігачів різного типу (наприклад, Люєнбергера повного порядку), використання еталонних (явних, неявних) моделей, сигнального i/або параметричного самонастроювання, адаптивних, нечітких та інших сучасних систем керування також дуже непроста [10-15], вимагає додаткових досліджень при суттєвих капітальних затратах.

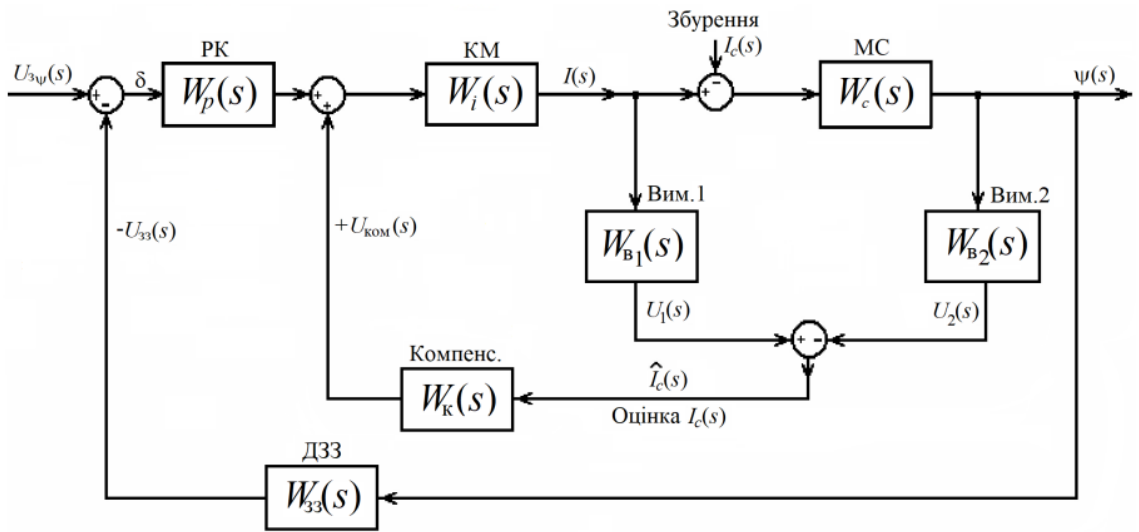

Рис. 2. Функціональна схема двоконтурної ССК, що забезпечує часткову інваріантність до $I_{c}(t)$

У статті пропонується досить простий метод введення у систему стабілізації властивостей часткової інваріантності до вітро-хвильового навантаження, заснований на непрямому визначенні основного збурення $I_{c}(s)$, відхиляючого судно від заданого курсу.

Як зазначено вище, для реалізації інваріантної системи керування необхідно знати точку прикладання збурення. Вважаємо, що основне збурення $I_{c}(s)$ приведено до кута повороту керма, що цілком допустимо $з$ позицій застосування загальної теорії автоматичного керування у даній постановці задачі.

На рис. 2 представлена функціональна схема двоканальної (комбінованої) ССК, що забезпечує, за рахунок використання додаткового компенсаційного зв'язку, досягнення часткової інваріантності до головного збурення.

На рис. 2 позначено: РК - регулятор курсового кута ч судна; КМ - замкнений контур керування кермовою машиною судна; МС - передатна функція моделі судна, заснована на описі Номото другого порядку; ДЗ3 - датчик зворотного зв'язку (курсового кута); Вим.1, Вим.2, Компенс. - відповідно, пристрої вимірювання та уведення компенсуючого збурення позитивного зворотного зв'язку в ССК.

Оцінку основного збурення проведемо за виразом, що витікає з структурної схеми, зображеної на рис. 2:

$$
I_{c}(s)=I(s)-\psi(s) / W_{c}(s)
$$

відповідно $\hat{I}_{c}(s)=U_{1}(s)-U_{2}(s)$, а $\hat{I}_{c}(s) \approx I_{c}(s)$, де $W_{c}(s)$ - передатна функція моделі судна (при стабілізації курсового кута $\psi$ ).

Очевидно, що цифрова чи аналогова реалізація виразу (3) потребує обчислення похідних з усіма витікаючими, відомими, технічними проблемами і обмеженнями. Врахуємо, що реальні пристрої вимірювання кута повороту керма і курсового кута $\psi$ володіють властивостями фільтрування і часто описуються аперіодичними ланками зі сталими часу $T_{\mathrm{c}}$ i $T_{\mathrm{T}}$, відповідно. Встановимо на виході датчика кута повороту керма фільтр з коефіцієнтом передачі та сталою часу, точно такими, як і у датчика курсового кута, а на виході датчика курсового кута - фільтр з коефіцієнтом передачі та сталою часу, такими, як у датчика кута повороту керма. Такий прийом дозволить спростити технічну реалізацію системи за рахунок отримання спільного знаменника у передатних функцій.

3 урахуванням викладеного вище, ділянку структурної схеми, що дозволяє оцінити основне збурення $I_{c}(s)$, наведено на рис. 3 .

Слід зазначити, що оцінене значення основного збурення буде завжди мати динамічну похибку, яка в найкращому випадку визначається інерційністю аперіодичної ланки другого порядку $\left(T_{\mathrm{c}} \cdot T_{\mathrm{T}}\right) \cdot s^{2}+\left(T_{\mathrm{c}}+T_{\mathrm{T}}\right) \cdot s+1$.

Збурення, оцінене за допомогою наведеної на рис. 2 структурної схеми, визначається виразом: 


$$
\hat{I}_{c}(s)=I_{c}(s) \cdot \frac{K_{\mathrm{T}}}{\left(T_{\mathrm{T}} \cdot s+1\right)} \cdot \frac{K_{\mathrm{c}}}{\left(T_{\mathrm{c}} \cdot s+1\right)} \cdot
$$

У вираз (4) входить складова $1 / W_{c}(s)$, згідно (3).

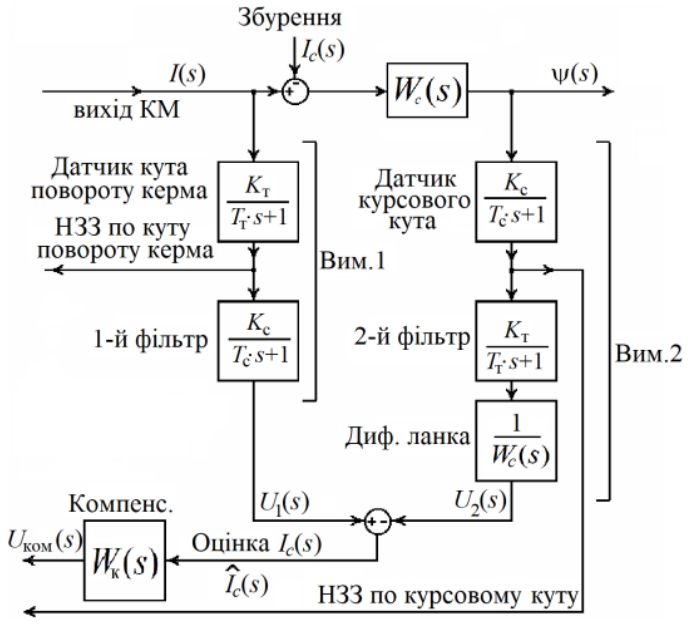

Рис. 3. Ділянка структурної схеми (див. рис. 2), яка реалізує оцінку основного збурення

Очевидно, що:

- результуюча точність оцінки $\hat{I}_{c}(s)$ залежить від точності технічної реалізації виразу $1 / W_{c}(s)$, яке, у свою чергу, також є спрощеною моделлю судна;

- у системі з датчиком курсового кута і обсервації оцінка буде грубіше, оскільки інерційність такого вимірювального каналу досить висока і порівнянна з інерційністю кермової машини;

- передатна функція ланки компенсуючого зв'язку $W_{\kappa}(s)=W_{i}^{-1}(s)$ не може бути точно реалізована, оскільки $W_{i}(s) \approx \frac{1 / k_{\mathrm{T}}}{2 \cdot T_{\mu 1}^{2} \cdot s^{2}+2 \cdot T_{\mu 1} \cdot s+1}$.

Тому приймаємо

$$
W_{\kappa}(s)=\frac{2 \cdot T_{\mu 1} \cdot s+1}{0,1 \cdot T_{\mu 1} \cdot s+1} \cdot k_{\mathrm{T}}
$$

що, у свою чергу, також є помітним спрощенням, заснованим на наближеній математичній моделі кермової машини судна.

Результати моделювання системи (див. рис. 3), з урахуванням дії компенсуючого основного збурення, наведено на рис. 4.

У якості вихідних даних для моделювання прийнято параметри багатоцільового судна криголамного типу 3 довжиною судна по конструктивній ватерлінії $L_{\text {квл }}=70,5$ м, осадкою на міделі $d_{\mathrm{M}}=3,5$ м, об'ємною водотоннажністю $W=2864 \mathrm{~m}^{3}$, сумарною потужністю $N=4600$ кВт СЕУ, при інтервалі швидкостей судна $V=2 . . .20$ вузл. Параметри моделі (2) наведені у табл. 1 і засновані на результатах ідентифікації $[6,7,9,16]$.

Таблиця 1 - Параметри моделі (2) судна

\begin{tabular}{|c|c|c|c|c|c|}
\hline$K$ & $v_{1}$ & $v_{2}$ & $T_{1}$ & $T_{2}$ & $T_{3}$ \\
\hline 0,031 & $-1,7 \cdot 10^{-3}$ & $6,1 \cdot 10^{-4}$ & 31 & 15 & 5 \\
\hline
\end{tabular}

Динаміка роботи кермової машини описана ПФ аперіодичної ланки зі сталою часу $T_{i}=3,5$ с. Моделювання проведено у середовищі MatLab/Simulink, з використанням методології, викладеної у [17-18].

На рис. 4 показані процеси зміни результуючого збурення (крива 1$)$ у моменти часу $t_{1}=2800 \mathrm{c}, t_{2}=5800 \mathrm{c}, t_{3}=8700 \mathrm{c}$ та $t_{4}=12000$ с. Це збурення викликає зміну курсу судна, та за рівнем приведено до кута повороту керма на $5 \circ$. Автокермовий відпрацьовує збурення за допомогою ПІД-регулятора - стабілізує курсовий кут $\psi$ на заданому ССК рівні у $15^{\circ}$. Параметри ПІД-регулятора обрані за допомогою синтезу замкненої системи так, щоб результуючі процеси зміни курсового куту ч відповідали настроюванню системи на технічний оптимум (за завданням).

При використанні запропонованої оцінкі $I_{c}(t)$ та за допомогою встановлення додаткового каналу компенсації результуючого збурення (див. рис. 3 і рис. 2), динаміка системи, навіть без зміни настроювання ПІД-регулятора 
автокермового, суттєво покращується. Це ілюструється кривою 3, наведеною на рис. 4, яка показує $\hat{I}_{c}(t)-$ оцінене значення $I_{c}(t)$, і кривою 4 - змінюванням курсового кута у частково-інваріантній до збурень системі.

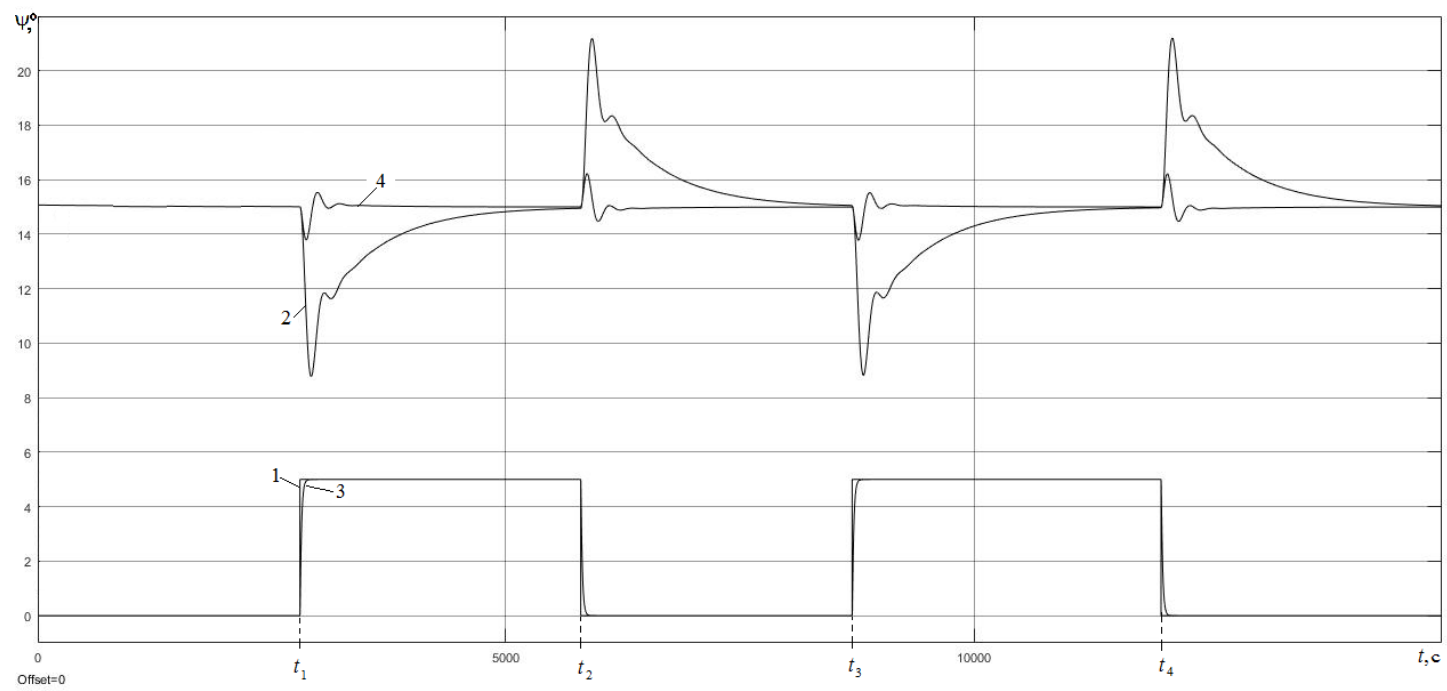

Рис. 4. Результати моделювання системи (див. рис. 2 та 3) з урахуванням дії компенсуючого основного збурення

\section{Висновки}

3 аналізу результатів математичного моделювання запропонованої системи стабілізації курсового кута морського судна можна визначити, що така система є дієвою і ефективно приглушує вітро-хвильові збурення на корпус судна. Наприклад, встановлено, що при умові компенсації результуючого збурення у $5^{\circ}$ на судно, 3 використанням класичної системи стабілізації «за відхиленням» і ПІД «технічно оптимального» регулятора автокермового, максимальне динамічне відхилення становить $6^{\circ}$ при часі регулювання (входження у 5 \% зону), близько 2200 с.

При аналогічних умовах навантажень, але 3 роботою запропонованої частково-інваріантної до збурень системи стабілізації курсу, отримуємо максимальне динамічне відхилення, близько до $1,3^{\circ}$ при часі регулювання (входження у $5 \%$ зону) до $200 \mathrm{c.}$

3 детальнішого аналізу запропонованої системи додатково можна визначити, що більш ефективна стабілізація курсу судна зумовлена підвищенням швидкодії автокермового - за рахунок упередженої дії на кермовий пристрій судна, сформованої каналом позитивного зворотного зв'язку за збуренням. Саме цій ефект визначає зменшення витрат пального і втрати ходового часу.

\section{Список використаних джерел}

[1] Острецов Г. Э., Клячко Л. М. Методы автоматизации управления движением корабля. - М.: Физматлит, 2009. 120 c.

[2] Вагущенко Л. Л., Цымбал Н. Н. Системы автоматического управления движением судна. - М.: ТрансЛит, 2007. 376 c.

[3] Антонов В. А., Письменный М. Н. Теоретические вопросы управления судном. - Владивосток: МГУ им. адм. Г. И. Невельского, 2007. 78 с.

[4] Юдин Ю. И., Сотников И. И. Математические модели плоскопараллельного движения судна. Классификация и критический анализ. - Мурманск, 2006. 95 с.

[5] Снопков В. И. Управление судном. - СПб.: Профессионал, 2004. 536 с.

[6] Юдин Ю. И., Пашенцев С. В. Идентификация математической модели судна. - М.: Моркнига, 2015.141 с.

[7] Ayulia Sitio Agisjaihc An Analysis Nomoto Gain and Norbin Parameter on Ship Turning Maneuver // IPTEK, The Journal for Technology and Science. 2010. Vol. 21. no. 2. Pp. 307-309.

[8] Седова Н. А. Интеллектуальная система автоматического управления курсом судна // Транспортное дело России. Спецвыпуск. 2006. № 7. С. 58-61.

[9] Golikov V. V., Golikov V. A., Volyanskaya Ya., Mazur O., Onishchenko O. A simple technique for identifying vessel model parameters // Earth and Environmental Science. 2018. Vol. 167. Pp. 135-139.

[10] Vichuzhanin V. Realization of a fuzzy controller with fuzzy dynamic correction // Central European Journal of Engineering. 2012. Vol. 2. no. 3. Pp. 392-398.

[11] Budashko V., Nikolskyi V., Onishchenko O., Khniunin S. Decision support system's concept for design of combined propulsion complexes // Eastern-European Journal of Enterprise Technologies. 2016. Vol. 3 (8(81)). Pp. 10-21. 
[12] Wen-Hsien Ho, Chen-Huei Hsieh, Jyh-Horng Chou Optimal course handling control for nonlinear ship maneuvering system // International Journal of Innovative Computing, Information and Control ICIC, International. 2010. Vol. 6. No. 10. Pp. 114-117.

[13] Шушляпин Е. А., Карапетьян В. А., Безуглая А. Е., Афонина А. А. Нелинейные регуляторы для удержания судна на заданной траектории при «сильных» маневрах // Труды СПИИРАН. 2017. Вып. 4(53). С. 178-200.

[14] Tomera M. Nonlinear controller design of a ship autopilot // Int. J. Appl. Math. Comput. Sci. 2010. Vol. 20. no. 2. Pp. 271-280.

[15] Yaohua Hu, Suwu Xu. Generalized predictive controller design for ship track keeping // ICCSNS International Journal of Computer Science and Network Security. 2010. Vol 9. No. 5. Pp. 236-239.

[16] Odegard V. Nonlinear Identification of Ship Autopilot Models // Norwegian University of Science and Technology, 2009. P. $100-107$.

[17] Zan Y. Research on Real-Time Simulation System of Ship Motion Based on Simulink // Open Mechanical Engineering Journal. 2014.Vol. 8. Pp. 820-827.

[18] Волянська Я. Б., Волянський С. М. Особливості побудови автоматичних систем керування рухом об'єктів морської робототехніки // Электротехнические и компьютерные системы. 2016. Вып. 23 (99). С. 39-44.

\section{References}

[1] G. Eh. Ostrecov, L. M. Klyachko "Metody avtomatizacii upravleniya dvizheniem korablya”. M.: Fizmatlit, 120 p., 2009.

[2] L. L. Vagushchenko, N. N. Cymbal "Sistemy avtomaticheskogo upravleniya dvizheniem sudna". M.: TransLit, 376 p., 2007.

[3] V. A. Antonov, M. N. Pis'mennyj “Teoreticheskie voprosy upravleniya sudnom”. Vladivostok: MGU im. adm. G. I. Nevel'skogo, 78 p., 2007.

[4] Yu. I. Yudin, I. I. Sotnikov "Matematicheskie modeli ploskoparallel'nogo dvizheniya sudna. Klassifikaciya i kriticheskij analiz". Murmansk, 95 p., 2006.

[5] V. I. Snopkov “Upravlenie sudnom”. SPb.: Professional, 536 p., 2004.

[6] Yu. I. Yudin, S. V. Pashencev "Identifikaciya matematicheskoj modeli sudna”. M.: Morkniga, 141 p., 2015.

[7] Ayulia Sitio Agisjaihc "An Analysis Nomoto Gain and Norbin Parameter on Ship Turning Maneuver". IPTEK, The Journal for Technology and Science., Vol. 21, no. 2, p 307-309, 2010.

[8] N. A. Sedova "Intellektual'naya sistema avtomaticheskogo upravleniya kursom sudna". Transportnoe delo Rossii. Specvypusk., № 7, p. 58-61, 2006.

[9] V. V. Golikov, V. A. Golikov, Ya. Volyanskaya, O. Mazur, O. Onishchenko "A simple technique for identifying vessel model parameters". Earth and Environmental Science., Vol. 167, p. 135-139, 2018.

[10] V. Vichuzhanin "Realization of a fuzzy controller with fuzzy dynamic correction". Central European Journal of Engineering., Vol. 2, no. 3, p. 392-398, 2012.

[11] V. Budashko, V. Nikolskyi, O. Onishchenko, S. Khniunin “Decision support system's concept for design of combined propulsion complexes". Eastern-European Journal of Enterprise Technologies., Vol. 3 (8(81)), p. 10-21, 2016.

[12] Wen-Hsien Ho, Chen-Huei Hsieh, Jyh-Horng Chou "Optimal course handling control for nonlinear ship maneuvering system". International Journal of Innovative Computing, Information and Control ICIC, International., Vol. 6, no. 10, p. 114$117,2010$.

[13] E. A. Shushlyapin, V. A. Karapet'yan, A. E. Bezuglaya, A. A. Afonina "Nelinejnye regulyatory dlya uderzhaniya sudna na zadannoj traektorii pri «sil'nyh» manevrah". Trudy SPIIRAN., Vyp. 4(53), p. 178-200, 2017.

[14] M. Tomera "Nonlinear controller design of a ship autopilot". Int. J. Appl. Math. Comput. Sci., Vol. 20, no. 2, p. 271-280, 2010.

[15] Yaohua Hu, Suwu Xu. "Generalized predictive controller design for ship track keeping”. ICCSNS International Journal of Computer Science and Network Security., Vol 9, no. 5, p. 236-239, 2010.

[16] V. Odegard "Nonlinear Identification of Ship Autopilot Models". Norwegian University of Science and Technology., p. 100 107, 2009.

[17] Y. Zan "Research on Real-Time Simulation System of Ship Motion Based on Simulink". Open Mechanical Engineering Journal., Vol. 8, p. 820-827, 2014.

[18] Ya. B. Volyans'ka, S. M. Volyans'kij “Osoblivosti pobudovi avtomatichnih sistem keruvannya ruhom ob'€ktiv mors'koï robototekhniki”. EHlektrotekhnicheskie i komp'yuternye sistemy., Vyp. 23 (99), p. 39-44, 2016. 